\title{
Pheochromocytoma and Adrenocortical Carcinoma: Morphological Characteristics in Endoscopic Ultrasound Imaging
}

\section{()(1) $(8 \Theta$}

\author{
Authors \\ Neslihan Özkul1, 2, Peter Herbert Kann1, 3
}

\begin{abstract}
Affiliations
1 Faculty of Medicine, University Hospital Giessen and Marburg, Philipps University, Centre for Endocrinology, Diabetology \& Osteology, Marburg, Germany

2 Clinic for Anaesthesiology, University Hospital Basel, Basel, Switzerland

3 German Centre for Endocrine Care, Frankfurt, Germany
\end{abstract}

Key words

ultrasound, adrenal gland, tumor

received 09.12.2020

accepted after revision $\quad 29.07 .2021$

Bibliography

Ultrasound Int Open 2021; 7: E64-E70

DOI 10.1055/a-1626-1678

ISSN 2199-7152

(c) 2021. The Author(s).

This is an open access article published by Thieme under the terms of the Creative Commons Attribution-NonDerivative-NonCommercial-License, permitting copying and reproduction so long as the original work is given appropriate credit. Contents may not be used for commecial purposes, or adapted, remixed, transformed or built upon. (https://creativecommons. org/licenses/by-nc-nd/4.0/)

Georg Thieme Verlag KG, Rüdigerstraße 14,

70469 Stuttgart, Germany

Correspondence

Ms. Neslihan Özkul

Centre for Endocrinology, Diabetology \& Osteology,

Philipps University Marburg Faculty of Medicine,

Baldingerstrasse

35043 Marburg

Germany

neslihan.oezkul@usb.ch

\section{ABSTRACT}

Purpose Pheochromocytoma (PCC) and adrenocortical carcinoma (ACC) are two rare endocrine diseases. Early diagnosis is crucial to significantly reduce morbidity and mortality. In this study, we used endoscopic ultrasound (EUS) for high-resolution imaging to investigate the endosonographic morphology pattern of PCC and ACC.

Materials and Methods This retrospective cohort study included 58 PCC/ACC lesions diagnosed by EUS imaging at two tertiary care centers between 1997 and 2015. The following groups were defined by histology or by the presence of a pheochromocytoma-associated syndrome without histological proof: bPCC (benign PCC), mPCC (malignant PCC), and ACC.

Results In our cohort, $\mathrm{mPCC}$ tended to be larger at the time of diagnosis $(n=5 ; 39.9 \pm 41.9 \mathrm{~mm})$ than bPCC $(n=46 ; 27.3 \pm$ $20.8 \mathrm{~mm}, P=0.548)$. ACC lesions were significantly larger $(n=7$; $50.6 \pm 14.8 \mathrm{~mm})$ than $\mathrm{bPCC}$ and $\mathrm{mPCC}(\mathrm{n}=51 ; 28.5 \pm 23.3 \mathrm{~mm}$, $\mathrm{P}=0.002)$. In EUS, bPCC and ACC lesions frequently appeared to have a round shape and nodular structure. bPCC and ACC tended to be more hyperechoic $(P=0.112$ and $P=0.558$, respectively) and heterogeneous $(P=0.501$ and $P=0.098$, respectively) than mPCC. Compared to PCC, ACC did not show high hyperperfusion $(P=0.022)$. In contrast to adenoma, all tumor entities showed hypo-/anechoic areas within the tumor $(\mathrm{P}<0.05)$.

Conclusion No significant differences in EUS morphology were found to reliably distinguish benign from malignant PCC and ACC lesions. However, EUS may be a reasonable alternative or complementary method to conventional imaging techniques for the early detection of these tumor entities.

\section{Introduction}

Pheochromocytoma (PCC) and adrenocortical carcinoma (ACC) are rare tumor entities. PCC occurs in 3-8 cases per million patients per year. For ACC, 1-2 per million patients are newly diagnosed every year [1-3]. While PCC, which often remains undiagnosed, may cause dramatic and life-threatening crises [4], ACC generally has a poor prognosis due to its high malignancy and the advanced 
disease state at which it is usually diagnosed $[1,5]$. Both PCC and ACC are associated with various hereditary diseases [1,4].

Early diagnosis and optimal treatment of PCC and ACC require a multimodal approach [6]. Thus far, standard imaging modalities include computed tomography $(\mathrm{CT})$, magnetic resonance imaging (MRI), scintigraphy with somatostatin analogs, and metaiodobenzylguanidine (MIBG), often used in combination [2, 3, 6, 7]. Endoscopic ultrasound (EUS) has also been considered a relevant diagnostic tool in adrenal gland imaging. In some cases, the high resolution of EUS allowed for the detection of smaller lesions missed by conventional imaging modalities like CT or MRI [8].

The aim of the present study was to analyze the power of EUS in the detection and differentiation of endosonographic characteristics, particularly tumor size, echogenicity, echostructure, and vascularization of benign and malignant PCC, as well as ACC.

\section{Material and Methods}

\section{Patients}

We retrospectively analyzed our database of 2328 adrenal lesion images that were acquired by EUS between January 1997 and March 2015 at two tertiary care centers. Inclusion criteria included histological evidence of PCC or ACC, or presentation of a pheochromocytoma-associated syndrome without histological examination. Four lesions without histological confirmation were classified as benign PCC (bPCC), due to patients not showing signs of malignancy at the time of examination. Histological confirmation of the other lesions was obtained after surgical resection. Malignancy was defined by the presence of metastases in non-chromaffin tissue such as bone, liver, or lymph nodes [2]. Subsequently, lesions were classified into three groups: bPCC, malignant PCC (mPCC), and ACC. Missing data points regarding morphology were defined as unclassified.

\section{Endoscopic Ultrasound}

EUS was performed using a Pentax FG 32 UA endosonoscope (Pentax Corporation, Tokyo, Japan) with a longitudinal 5-7.5 MHz sector array probe in combination with a Hitachi EUB 420 or EUB 525 ultrasound unit (Hitachi Medical Corporation, Tokyo, Japan). All investigations were performed by a single experienced examiner. Patients received $25-50 \mathrm{mg}$ pethidine, $5-20 \mathrm{mg}$ diazepam, and $0.125-0.5 \mathrm{mg}$ atropine for premedication. The examination time was approximately 30-40 minutes.

The ultrasound probe was placed in the duodenal bulb or antrum, and in the proximal corpus region of the stomach to investigate the right and left adrenal glands, respectively. Extra-adrenal locations were viewed from the proximal esophagus down the horizontal part of the duodenum [8-10]. Pathological lesions were compared with the adjacent kidney and adrenal gland [8].

\section{Other imaging modalities}

All EUS-assessed lesions were retrospectively compared with the findings in corresponding MRI, CT, and MIBG scans, if available, to evaluate the diagnostic efficacy of EUS [8].

\section{Endosonographic morphological pattern}

PCC and ACC were characterized by EUS regarding location, tumor size, shape, echogenicity ( $\triangleright$ Figs. 1-3), echostructure, architecture, boundaries, and vascularization [8].

\section{Statistical analysis}

Statistical analyses were performed using SPSS Version 23.0 (SPSS, Chicago, IL, USA). For descriptive statistics, results are presented as frequency (\%) or mean \pm SD and range. P-values $<0.05$, based on chi-square test, Fisher's exact test, and Mann-Whitney U test, were considered significant.

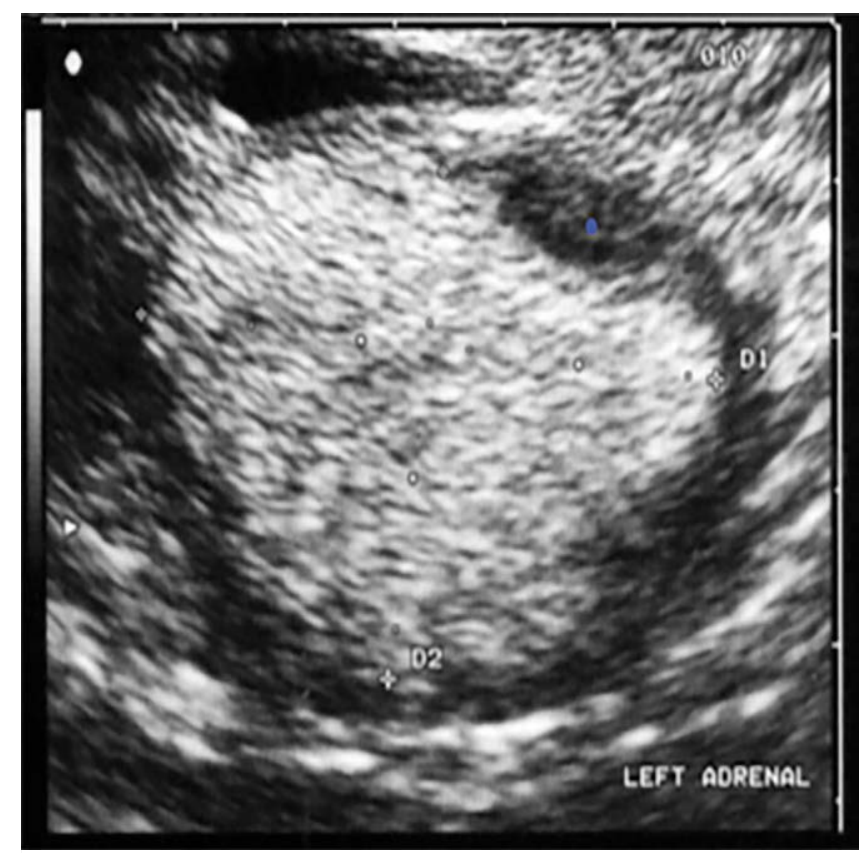

- Fig. 1 Hyperechoic lesion of the left adrenal.

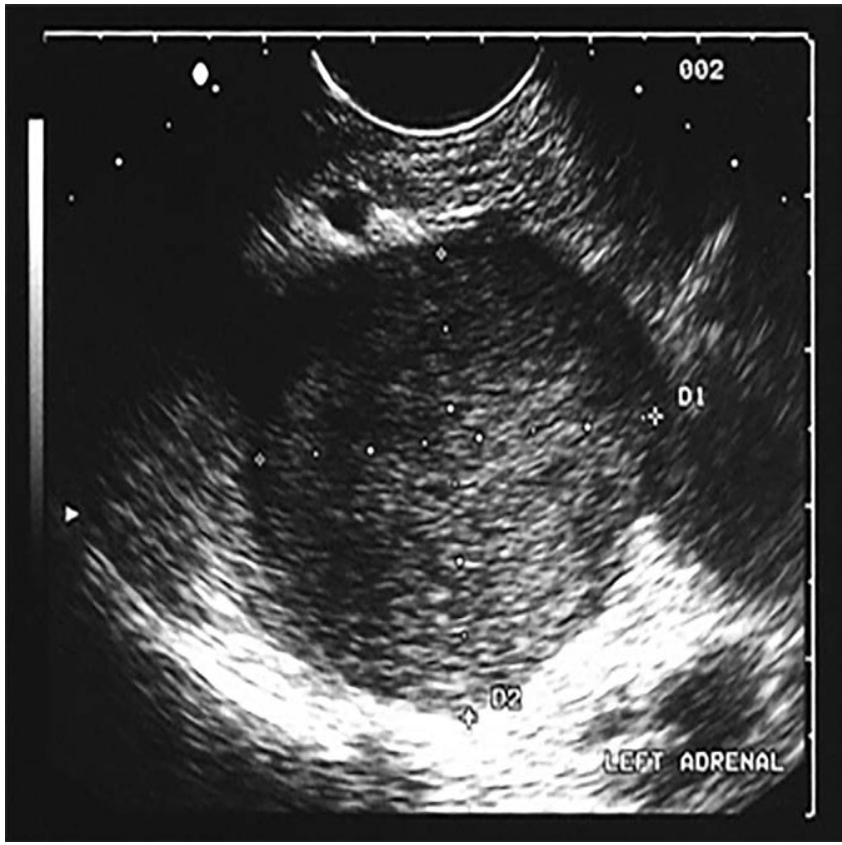

- Fig. 2 Isoechoic lesion of the left adrenal. 


\section{Data Availability Statement}

Data supporting the findings of this study are available upon request from the corresponding author.

\section{Ethics Approval}

Our local research ethics committee certified that this retrospective study does not require formal evaluation by the ethics committee as data were obtained during routine diagnostic procedures and were strictly de-identified.

\section{Results}

Among all EUS adrenal lesion images, we identified a total of 58 lesions, corresponding to 38 patients, for inclusion in this study. Of these, 27 patients with 46 lesions were classified as bPCC, 4 patients with 5 lesions as MPCC, and 7 patients with 7 lesions as ACC.

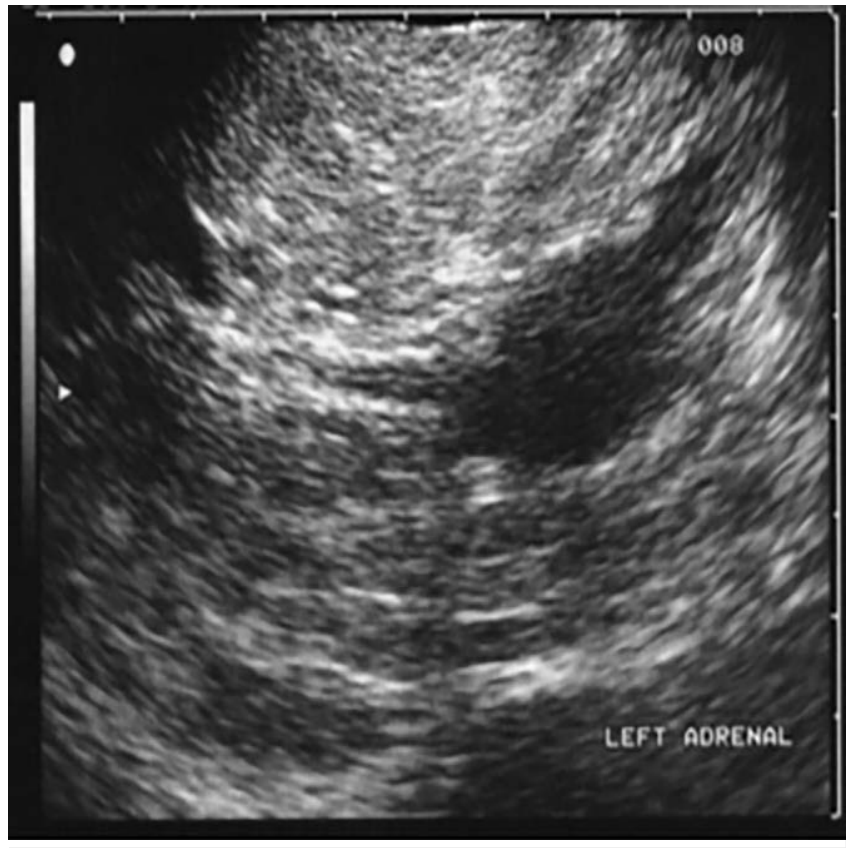

- Fig. 3 Hypoechoic lesion of the left adrenal.
Among bPCC patients, 16 were male and 11 were female; mean age was $47.0 \pm 14.6$ years. The mean diameter of bPCC was $27.3 \pm 20.8 \mathrm{~mm}$ (range: $7-94 \mathrm{~mm}$ ). 23 lesions were located on the left side (50\%) and 18 lesions on the right (39.1\%). The remaining 5 lesions were extra-adrenal (10.9\%). The lesions of 11 patients were associated with hereditary syndromes, while those of the remaining patients (59.3\%) were sporadic. The most frequent morphological patterns were hyperechogenicity (65.2\%) (> Fig. 4), slight to strong heterogeneity (69.6\%), round shape (93.5\%), nodular structure (100\%), encapsulated (76.1\%), hypo-/anechoic areas within the tumor (58.7\%), and mild to high hyperperfusion (63.1\%).

$\operatorname{mPCC}(n=5$ lesions) included two female and two male patients with a mean age of $42.3 \pm 22.3$ years. Three lesions were located on the right side and two lesions on the left. All tumors were sporadic. Mean diameter was $39.9 \pm 41.9 \mathrm{~mm}$ (range: $14.8-113.3 \mathrm{~mm}$ ). Morphological patterns of mPCC imaged by EUS included hypoechogenicity (60\%) ( Fig. 4), homogeneity (60\%), round shape (100\%), nodular structure ( $80 \%$ ), without a capsule, sharp to blurry margins (60\%), lack of hypo-/anechoic areas within the tumor (60\%), and mild hyperperfusion (60\%).

In 11 patients with PCC, the lesions were associated with hereditary syndromes including multiple endocrine neoplasia II (29.0\%), von Hippel-Lindau syndrome (3.2\%), and neurofibromatosis type 1 (3.2\%). Among these, eight patients showed bilateral pheochromocytoma consistent with the benign morphological criteria.

Among ACC patients ( $n=7$ lesions), mean age was $46.3 \pm 6.9$ years. All seven patients were female. Most lesions were located on the left side $(n=5,71.4 \%)$. Mean lesion diameter was $50.6 \pm$ $14.8 \mathrm{~mm}$ (range: $31.0-68.2 \mathrm{~mm}$ ), with three of the lesions presenting larger than $6 \mathrm{~cm}(42.9 \%)$. The most frequent morphological patterns of this group were hyperechogenicity (71.4\%), slight to strong heterogeneity (100\%), round shape (100\%), and nodular structure (85.7\%). The majority of these tumors (85.7\%) presented hypo-/anechoic areas within the tumor and no hyperperfusion (57.1\%).

There were no significant differences between groups regarding endosonographic morphological patterns, such as tumor size, echogenicity, echostructure, and vascularization (Table 1). However, benign PCC tended to be more hyperechoic $(P=0.112)$ than

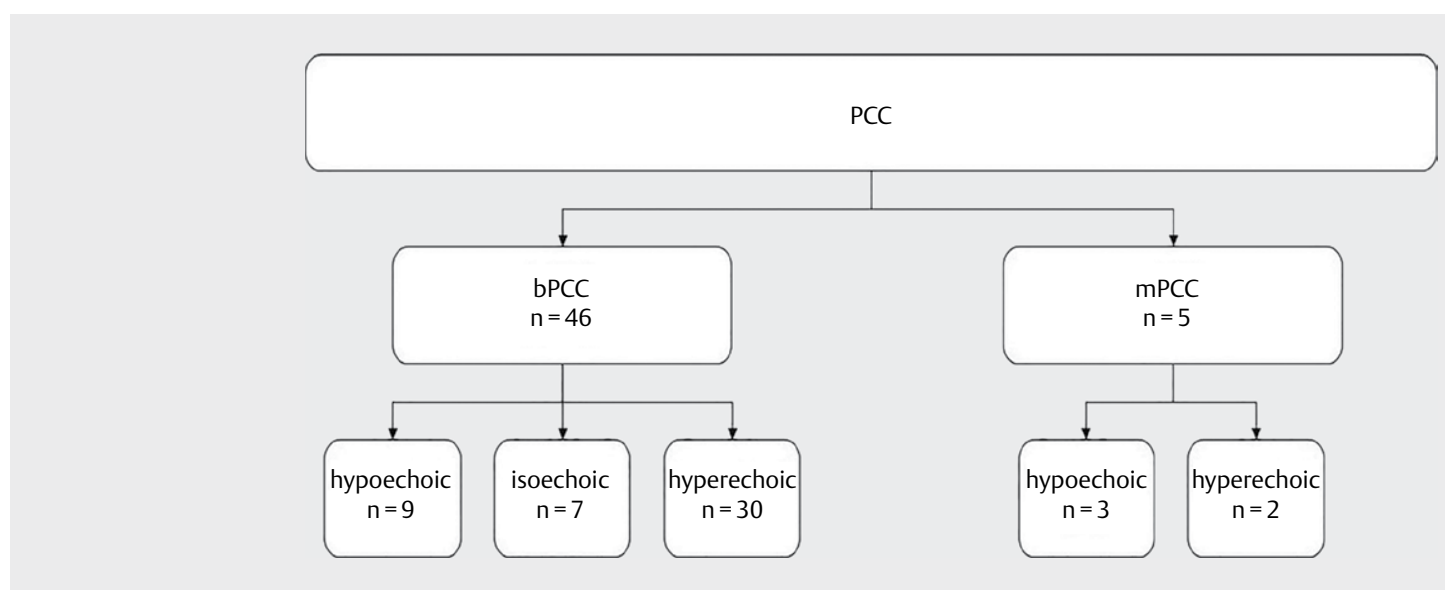

- Fig. 4 Echogenicity of the different tumor entities. bPCC: benign pheochromocytoma; mPCC: malignant pheochromocytoma. 
malignant PCC. In contrast to PCC, ACC did not show high hyperperfusion $(P=0.022)$ but presented with a larger tumor size $(P=0.002)$ (Tables $1 \& 2)$.

EUS imaging of individual tumors was compared with findings on respective MRI, CT, and MIBG scintigraphy scans (Table 3 ). Findings based on MIBG scintigraphy $(n=50)$ were consistent with the EUS imaging diagnosis of PCC in $88 \%$ of all PCC lesions. MIBG scintigraphy was negative for $12 \%$ of lesions diagnosed by EUS. Three lesions ( $50 \%$ ), which could not be visualized by MIBG scintigraphy were malignant. The mean diameter of the MIBG-negative lesions was $28.9 \pm 7.8 \mathrm{~mm}$ (range: $15.4-35.8 \mathrm{~mm}$ ).

\section{Discussion}

In agreement with previous studies $[8,11]$, this retrospective study found malignant adrenal gland tumors to be larger than benign adrenal lesions. However, EUS-based morphological distinction between benign and malignant PCC as well as ACC remains difficult, since a reliable distinction between these tumor entities cannot be determined based on endosonographic morphological patterns including tumor size, echogenicity, echostructure, and vascularization.

The distribution of sex and age in patients with benign or malignant PCC in this study is in line with recent studies [11, 12]. Age distribution and presence of a higher proportion of females (100\%) presenting with ACC lesions also corresponds well with previous analyses [3]. The majority of PCC cases arise sporadically, and in approximately $25 \%$ of cases, PCC is hereditary $[13,14]$. Sporadic PCC appears to have a greater risk of malignancy [13]. $50 \%$ of cases with PCC were associated with multiple endocrine neoplasia II, $15-20 \%$ of cases with von Hippel-Lindau syndrome, and $5 \%$ of cases with neurofibromatosis type $1[7,15]$. Tumors of pheochromocytoma-associated syndromes occur bilaterally and are less frequently malignant [15]. 15-20\% of PCC lesions arise in extra-adrenal chromaffin cells [16]. In general, $10-15 \%$ of PCCs and $20-50 \%$ of extra-adrenal PCCs are malignant [17]. In our study, all extra-adrenal PCCs were benign in nature. Given the overall small number of cases in this study, this result should not be overinterpreted. No side preference for PCC and ACC has been reported in the recent literature [18].

In our study, PCC and ACC showed differences regarding tumor size. Allolio and Fassnacht [19] reported the size of adrenal tumors measured by CT or MRI to be a good indicator of malignancy. Lesions larger than $6 \mathrm{~cm}$ are highly suspicious for malignancy and should be surgically removed. Interestingly, the malignant lesions detected had smaller diameters. Thus, the resolution provided by EUS may be better than conventional methods and enable the detection of small tumors at an early stage of disease [20]. The reported mean tumor size of PCC detected either by conventional imaging techniques or after surgical removal ranged from 2.9 to $5.5 \mathrm{~cm}[15,21]$. Thus, our mean tumor size of $2.9 \pm 2.3 \mathrm{~cm}$ in EUS images was at the lower range of reported values. In addition, we found no significant difference in tumor size between patients with benign and malignant lesions. Kann et al. [8] reported that benign PCCs tended to be smaller than malignant PCCs. However, values did not reach significance. One reason may be that EUS was performed in patients for follow-up assessment of their lesions. In this way, small recurrences and metastases
- Table 1 Clinical and endosonographic characteristics of the different tumor entities. bPCC: benign pheochromocytoma; mPCC: malignant pheochromocytoma; ACC: adrenocortical carcinoma

\begin{tabular}{|c|c|c|c|}
\hline & \multicolumn{2}{|c|}{ Characteristics } & $P$-value \\
\hline & \multicolumn{2}{|c|}{$\begin{array}{l}\text { Mean age in years } \\
\text { mean } \pm \text { SD }\end{array}$} & \\
\hline bPCC $(n=27)$ & \multicolumn{2}{|l|}{$47.0( \pm 14.6)$} & \multirow{2}{*}{$P=0.589$} \\
\hline $\mathrm{mPCC}(\mathrm{n}=4)$ & \multicolumn{2}{|l|}{$42.3( \pm 22.3)$} & \\
\hline $\operatorname{ACC}(n=7)$ & \multicolumn{2}{|c|}{$46.3( \pm 6.9)$} & \multirow{2}{*}{$P=1.000$} \\
\hline \multirow[t]{3}{*}{$\operatorname{PCC}(n=31)$} & \multicolumn{2}{|l|}{$46.4( \pm 15.4)$} & \\
\hline & \multicolumn{2}{|l|}{ Sex, n (\%) } & \\
\hline & Male & Female & \\
\hline bPCC $(n=27)$ & $16(59.3 \%)$ & $11(40.7 \%)$ & \multirow{2}{*}{$P=1.000$} \\
\hline $\mathrm{mPCC}(\mathrm{n}=4)$ & $2(50 \%)$ & $2(50 \%)$ & \\
\hline $\operatorname{ACC}(n=7)$ & $0(0 \%)$ & $7(100 \%)$ & \multirow{2}{*}{$P=0.009$} \\
\hline \multirow[t]{3}{*}{$\operatorname{PCC}(n=31)$} & $18(58.1 \%)$ & $13(41.9 \%)$ & \\
\hline & \multicolumn{2}{|l|}{ Side, n (\%) } & \\
\hline & Left & Right & \\
\hline bPCC $(n=46)$ & $23(50 \%)$ & $18(39.1 \%)$ & \multirow{2}{*}{$P=0.637$} \\
\hline $\operatorname{mPCC}(n=5)$ & $2(40 \%)$ & $3(60 \%)$ & \\
\hline $\operatorname{ACC}(n=7)$ & $5(71.4 \%)$ & $2(28.6 \%)$ & \multirow{2}{*}{$P=0.692$} \\
\hline \multirow[t]{2}{*}{$\operatorname{PCC}(n=51)$} & 25 (49.0\%) & $21(41.2 \%)$ & \\
\hline & \multicolumn{2}{|c|}{$\begin{array}{l}\text { Mean diameter in } \mathrm{mm} \\
\text { mean } \pm \mathrm{SD}\end{array}$} & \\
\hline bPCC $(n=46)$ & \multicolumn{2}{|c|}{$27.3( \pm 20.8)$} & \multirow{2}{*}{$P=0.548$} \\
\hline $\operatorname{mPCC}(n=5)$ & \multicolumn{2}{|l|}{$39.9( \pm 41.9)$} & \\
\hline $\operatorname{ACC}(n=7)$ & \multicolumn{2}{|l|}{$50.6( \pm 14.8)$} & \multirow{2}{*}{$P=0.002$} \\
\hline \multirow[t]{2}{*}{$\operatorname{PCC}(n=51)$} & \multicolumn{2}{|l|}{$28.5( \pm 23.3)$} & \\
\hline & \multicolumn{2}{|c|}{ Hyperechoic, n (\%) } & \\
\hline bPCC $(n=46)$ & $30(65.2 \%)$ & & $\mathrm{P}=0.112$ \\
\hline $\operatorname{mPCC}(n=5)$ & $2(40 \%)$ & & $p=0.112$ \\
\hline $\operatorname{ACC}(n=7)^{* *}$ & $5(71.4 \%)$ & & \\
\hline $\operatorname{PCC}(n=51)$ & $32(62.8 \%)$ & & \\
\hline & Heterogenec & 5, n (\%) & \\
\hline $\mathrm{bPCC}(\mathrm{n}=46)$ & $32(69.6 \%)$ & & $P=0501$ \\
\hline $\operatorname{mPCC}(n=5)$ & $2(40 \%)$ & & $p=0.301$ \\
\hline $\operatorname{ACC}(n=7)^{* * *}$ & $5(71.4 \%)$ & & \\
\hline $\operatorname{PCC}(n=51)$ & 34 (66.7\%) & & \\
\hline & Hyperperfus & n, n (\%) & \\
\hline bPCC $(n=46)$ & $29(63.1 \%)$ & & $P=1000$ \\
\hline $\operatorname{mPCC}(n=5)$ & $3(60 \%)$ & & $p=-1.000$ \\
\hline $\mathrm{ACC}(\mathrm{n}=7)$ & $0(0 \%)$ & & ברח00 \\
\hline $\operatorname{PCC}(n=51)$ & $32(62.7 \%)$ & & $P=0.022$ \\
\hline & $\begin{array}{l}\text { Hypo-/anech } \\
\text { within the ti }\end{array}$ & $\begin{array}{l}\mathrm{c} \text { areas } \\
\text { or, } \mathrm{n}(\%)\end{array}$ & \\
\hline bPCC $(n=46)$ & 27 (58.7\%) & & $\mathrm{D}=0641$ \\
\hline $\operatorname{mPCC}(n=5)$ & $2(40 \%)$ & & $r-0.041$ \\
\hline $\operatorname{ACC}(n=7)^{* * * *}$ & $6(85.7 \%)$ & & \\
\hline PCC $(n=51)$ & $29(56.9 \%)$ & & \\
\hline
\end{tabular}


- Table 2 Typical EUS features in the different tumor entities. bPCC: benign pheochromocytoma; mPCC: malignant pheochromocytoma; ACC: adrenocortical carcinoma

\begin{tabular}{|c|c|c|c|}
\hline $\begin{array}{l}\text { Morphology/ } \\
\text { position }\end{array}$ & bPCC $(n=46)$ & $\operatorname{mPCC}(n=5)$ & $\operatorname{ACC}(n=7)$ \\
\hline $\begin{array}{l}\text { Echogenicity, } \\
n(\%)\end{array}$ & $\begin{array}{l}\text { Hyperechoic, } \\
30 \text { (65.2\%) }\end{array}$ & $\begin{array}{l}\text { Hypoechoic, } \\
3(60 \%)\end{array}$ & $\begin{array}{l}\text { Hyperechoic, } \\
5(71.4 \%)\end{array}$ \\
\hline $\begin{array}{l}\text { Echostructure, } \\
\mathrm{n}(\%)\end{array}$ & $\begin{array}{l}\text { Heterogeneous, } \\
32(69.5 \%)\end{array}$ & $\begin{array}{l}\text { Homogeneous, } \\
3(60 \%)\end{array}$ & $\begin{array}{l}\text { Strongly } \\
\text { heterogeneous, } \\
5(71.4 \%)\end{array}$ \\
\hline Form, n (\%) & $\begin{array}{l}\text { Round, } \\
43 \text { (93.5\%) }\end{array}$ & $\begin{array}{l}\text { Round, } \\
5(100 \%)\end{array}$ & $\begin{array}{l}\text { Round, } \\
7(100 \%)\end{array}$ \\
\hline $\begin{array}{l}\text { Architecture, } \\
n(\%)\end{array}$ & $\begin{array}{l}\text { Nodular, } \\
46(100 \%)\end{array}$ & $\begin{array}{l}\text { Nodular, } \\
4(80 \%)\end{array}$ & $\begin{array}{l}\text { Nodular, } \\
6(85.7 \%)\end{array}$ \\
\hline $\begin{array}{l}\text { Boundaries, } \\
\mathrm{n}(\%)\end{array}$ & $\begin{array}{l}\text { With a } \\
\text { "capsule", } \\
35(76.1 \%)\end{array}$ & $\begin{array}{l}\text { With a "capsule" } \\
\text {-sharp margin } \\
\text { without a } \\
\text { "capsule", } \\
4(80 \%)\end{array}$ & $\begin{array}{l}\text { With a } \\
\text { "capsule"- } \\
\text { blurry margin, } \\
6(85.7 \%)\end{array}$ \\
\hline $\begin{array}{l}\text { Hypoechoic/ } \\
\text { echo-free areas } \\
\text { within the } \\
\text { tumor, } n(\%)\end{array}$ & $\begin{array}{l}\text { Yes, } \\
27(58.7 \%)\end{array}$ & $\begin{array}{l}\text { No, } \\
3(60 \%)\end{array}$ & $\begin{array}{l}\text { Yes, } \\
6(85.7 \%)\end{array}$ \\
\hline $\begin{array}{l}\text { Vascularization, } \\
\mathrm{n}(\%)\end{array}$ & $\begin{array}{l}\text { Mild hyperper- } \\
\text { fusion, } \\
24(52.2 \%)\end{array}$ & $\begin{array}{l}\text { Mild hyperperfu- } \\
\text { sion, } \\
3(60 \%)\end{array}$ & $\begin{array}{l}\text { No } \\
\text { hyperperfusion, } \\
4(57.1 \%)\end{array}$ \\
\hline $\begin{array}{l}\text { Localization, } \\
\mathrm{n}(\%)\end{array}$ & $\begin{array}{l}\text { Adrenal, } \\
41 \text { (89.1\%) }\end{array}$ & $\begin{array}{l}\text { Adrenal, } \\
5(100 \%)\end{array}$ & $\begin{array}{l}\text { Adrenal, } \\
7(100 \%)\end{array}$ \\
\hline
\end{tabular}

- Table 3 Different imaging modalities used in this cohort. bPCC: benign pheochromocytoma; mPCC: malignant pheochromocytoma; CT: computed tomography; MRI: magnetic resonance imaging; MIBG scintiscan: metaiodobenzylguanidine scintiscan.

\begin{tabular}{|l|l|l|}
\hline & $\begin{array}{l}\text { Total number of } \\
\text { investigations }\end{array}$ & $\begin{array}{l}\text { No tumor } \\
\text { detected }\end{array}$ \\
\hline bPCC & & \\
\hline CT, n (\%) & $21(100 \%)$ & $0(0 \%)$ \\
\hline MRI, n (\%) & $33(100 \%)$ & $1(3 \%)$ \\
\hline MIBG scintiscan, $n(\%)$ & $45(100 \%)$ & $3(6.7 \%)$ \\
\hline mPCC & & $1(20 \%)$ \\
\hline CT, n (\%) & $5(100 \%)$ & $0(0 \%)$ \\
\hline MRI, n (\%) & $3(100 \%)$ & $3(60 \%)$ \\
\hline MIBG scintiscan, $n(\%)$ & $5(100 \%)$ & \\
\hline
\end{tabular}

at an early stage could be detected using EUS [8]. Previous reports also show no significant difference in tumor size between malignant and benign PCC [22]. Therefore, the ability of EUS imaging to detect small lesions missed by routine diagnostic methods could be a good indicator of its superior sensitivity. Concerning small endocrine tumors in the pancreas, EUS has been proven to detect lesions with a diameter as small as $1-2 \mathrm{~mm}$ [20].
Benign PCC visualized by EUS tended to be more hyperechoic and heterogeneous and to have more signs of hyperperfusion than malignant PCC. Lesions of the PCC groups were round and nodular. Correspondingly, Kann et al. [8] observed hyperechogenicity only in benign lesions. Laparoscopic ultrasound imaging of adrenal tumors during laparoscopic adrenalectomy revealed PCC to be clearly heterogeneous [23]. Schwerk et al. [24] described sonographic features of PCC compared to renal parenchyma (as a reference tissue) as being isoechoic or hypoechoic and heterogeneous in mass. All were encapsulated or well delimited, as well as round or ovoid. $32 \%$ of these tumors showed cystic components. Pathological findings of adrenal masses are usually associated with necrosis, signs of internal hemorrhage, and cystic areas with old blood or necrotic debris [15, 24]. Hyperechoic features in ultrasound imaging may demonstrate cystic and necrotic changes and acute hemorrhage in a PCC [15]. Collienne et al. [10,25] described adenomas on EUS as hypoechoic and slightly heterogeneous lesions with no hyperperfusion and no hypo-/anechoic areas within the tumor. In comparison to adenomas, benign PCCs and ACCs tended to be more hyperechoic. Similar to adenomas, malignant PCCs presented hypoechoic on EUS. A significant difference between these tumor entities was that, in contrast to adenomas, PCCs and ACCs showed hypo-/anechoic areas within the tumor $(P<0.05)[10,25]$.

MRI and CT are common imaging methods used initially for the high sensitivity localization of PCC. However, the specificity is less than optimal [26]. The sensitivity of CT for detecting lesions with a diameter above $1 \mathrm{~cm}$ ranges between 78 and $98 \%$ while the specificity ranges between 29 and $92 \%$ [26]. For lesions of the same size, MRI has a sensitivity of $93-100 \%$ and a specificity of $50-100 \%$ [26]. Studies using non-spiral CT techniques were not able to identify tumors with a diameter $<1 \mathrm{~cm}$. Lesions ranging from $1-3 \mathrm{~cm}$ could be identified by CT in $30 \%$ of cases, and those with a diameter $>3 \mathrm{~cm}$ were identified in $95 \%$ of cases [27]. Due to their strong hyperperfusion, PCCs have a strong hyperintensity on T2-weighted MRI images [15, 26]. PCCs with a heterogeneous appearance, especially if they are cystic, may show less signal intensity on T2weigthed MRI. However, T2-weighted signaling intensity can also be caused by different adrenal masses such as adenomas, carcinomas, hematomas, or hemorrhage [24]. In cases of intra-cytoplasmic fat, PCC can mimic adenoma [15] and show $\leq 10 \mathrm{HU}$ attenuation on unenhanced CT scans as well as loss of signal on chemical-shift imaging. In some cases, these tumors can mimic the characteristics of ACC and metastases by showing rapid contrast enhancement and slow washout [7]. With 71\%, MIBG-negative scintigraphy cases show a higher rate of malignancy. Some MIBG-negative tumors are associated with von Hippel-Lindau syndrome, while the MIBG-negative presentation may also be caused by a low expression of norepinephrine transporter, metastasized tumors, SDHB gene mutations, or PCC with necrosis. MIBG scintigraphy has a high specificity (95-100\%) and good sensitivity (77$90 \%)$ for PCC detection $[7,8,26,28]$. One possible reason for the superior detection of MIBG-negative PCCs by EUS could be its high resolution compared with conventional imaging methods and its independence regarding tracer uptake [8].

In contrast to PCCs, ACCs appear with no hyperperfusion. When using ultrasound, malignant lesions showed inhomogeneous echotexture with increasing size [3]. On other imaging like MRI or CT, 
ACCs often appear as large heterogeneous and locally aggressive adrenal masses [1]. Compared with adenomas, ACCs seem to be larger, heterogeneous, lobulated, and with areas of hemorrhage and necrosis [3]. In general, adenomas are often incidentally discovered, homogeneous, small, and nonaggressive lesions with stable growth [1]. Using MRI, ACCs appear heterogeneous because of hemorrhage and necrosis on both T1- and T2-weighted imaging. On unenhanced CT scans, larger signs of necrosis are more indicative of malignancy [29].

In conclusion, EUS is a minimally invasive imaging method that provides high resolution for both diagnostic and therapeutic purposes. EUS may be valuable in the early detection of PCC, which can be associated with genetic syndromes. Given the high resolution of the method, metastases or recurrences often missed by conventional diagnostic methods can be identified at an earlier stage of disease. EUS may provide additional useful information for surgical planning [8]. An important limitation of EUS is the difficulty to distinguish between different tumor entities, especially in cases of postoperative inflammatory changes or modified anatomical situations. Possible complications of EUS procedures include perforation, aspiration, and bacteremia [10,30]. However, none of these have been observed in our series. Due to its two-dimensional representation of tumors, EUS does not allow for precise calculation of the actual tumor volume [10] $>$ Tables 1-3.

The present study revealed no significant differences in EUS morphology patterns to reliably distinguish between benign and malignant PCC and ACC. Due to the low incidence of these tumor entities and the lack of histological confirmation of the four lesions of bPCC, the results may not have reached statistical significance. Furthermore, in some cases, information like vascularization of the lesions was missing, and additional imaging was not performed on all patients.

Nevertheless, EUS might be a good alternative and/or complementary method to conventional imaging techniques without the use of contrast media and exposure to radiation in the case of suspected sporadic and especially hereditary PCC and/or ACC [10].

\section{Acknowledgements}

We are grateful to Allison Dwileski, Clinic for Anaesthesiology, University Hospital Basel, and Maike Collienne, for making a significant non-author contribution by revising the manuscript.

\section{Conflict of Interest}

The authors declare that they have no conflict of interest.

\section{References}

[1] Ranathunga DS, Cherpak LA, Schieda $N$ et al. Macroscopic fat in adrenocortical carcinoma: A systematic review. Am J Roentgenol 2020; 214: 390-394. doi: 10.2214/AJR.19.21851

[2] Sbardella E, Grossman AB. Pheochromocytoma: An approach to diagnosis. Best Pract Res Clin Endocrinol Metab 2020; 34. doi:10.1016/j.beem.2019.101346
[3] Ahmed AA, Thomas AJ, Ganeshan DM et al. Adrenal cortical carcinoma: pathology, genomics, prognosis, imaging features, and mimics with impact on management. Abdom Radiol 2020; 45. doi:10.1007/s00261-019-02371-y

[4] Neumann HPH, Young WF, Eng C. Pheochromocytoma and Paraganglioma. N Engl J Med 2019; 381: 552-565. doi: 10.1056/nejmra1806651

[5] Shetty I, Fuller S, Raygada M et al. Adrenocortical carcinoma masquerading as pheochromocytoma: A histopathologic dilemma. Endocrinol Diabetes Metab Case Reports 2020; 2020. doi:10.1530/ EDM-19-0147

[6] Kaltsas GA, Besser GM, Grossman AB. The diagnosis and medical management of advanced neuroendocrine tumors. Endocr Rev 2004; 25: 458-511. doi: 10.1210/er.2003-0014

[7] Low G, Dhliwayo H, Lomas D]. Adrenal neoplasms. Clin Radiol 2012; 67: 988-1000. doi: 10.1016/j.crad.2012.02.005

[8] Kann PH, Wirkus B, Behr T, et al. Endosonographic imaging of benign and malignant pheochromocytomas. J Clin Endocrinol Metab 2004; 89: 1694-1697. doi: 10.1210/jc.2003-031709

[9] Kann PH. Endoscopic Ultrasound in Endocrinology: Imaging of the Adrenals and the Endocrine Pancreas. Front Horm Res 2016; 45: 46-54. doi: 10.1159/000442277

[10] Collienne M, Timmesfeld N, Bergmann SR et al. Adrenal Incidentaloma and Subclinical Cushing's Syndrome: A Longitudinal Follow-Up Study by Endoscopic Ultrasound. Ultraschall der Medizin 2017; 38: 411-419. doi: 10.1055/s-0041-107996

[11] Dhir M, Li W, Hogg ME et al. Clinical Predictors of Malignancy in Patients with Pheochromocytoma and Paraganglioma. Ann Surg Oncol 2017; 24: 3624-3630. doi: 10.1245/s10434-017-6074-1

[12] Barski D. Management and follow up of extra-adrenal phaeochromocytoma. Cent Eur J Urol 2014; 67: 156-161. doi: 10.5173/ ceju.2014.02.art8

[13] Brancíková D, Mechl Z, Adam Z et al. Patient with inoperable pheochromocytoma. Curr Oncol 2015; 22: e216-e219. doi: 10.3747/ co.22.2324

[14] Beck O, Fassbender W], Beyer P et al. Pheochromocytoma in childhood: implication for further diagnostic procedures. Acta Paediatr 2004; 93: 1630-1634

[15] Katabathina VS, Rajebi H, Chen M et al. Genetics and imaging of pheochromocytomas and paragangliomas: current update. Abdom Radiol 2020; 45: 928-944. doi: 10.1007/s00261-019-02044-w

[16] Fang F, Ding L, He Q et al. Preoperative Management of Pheochromocytoma and Paraganglioma. Front Endocrinol (Lausanne) 2020; 11. doi: $10.3389 /$ fendo.2020.586795

[17] Pappachan JM, Tun NN, Arunagirinathan G et al. Pheochromocytomas and Hypertension. Curr Hypertens Rep 2018; 20. doi: 10.1007/ s11906-018-0804-z

[18] Iñiguez-Ariza NM, Kohlenberg JD, Delivanis DA et al. Clinical, Biochemical, and Radiological Characteristics of a Single-Center Retrospective Cohort of 705 Large Adrenal Tumors. Mayo Clin Proc Innov Qual Outcomes 2018; 2: 30-39. doi: 10.1016/j.mayocpiqo.2017.11.002

[19] Allolio B, Fassnacht M. Clinical review: Adrenocortical carcinoma: Clinical update. J Clin Endocrinol Metab 2006; 91: 2027-2037. doi: 10.1210/jc.2005-2639

[20] Kann PH, Balakina E, Ivan D et al. Natural course of small, asymptomatic neuroendocrine pancreatic tumours in multiple endocrine neoplasia type 1: An endoscopic ultrasound imaging study. Endocr Relat Cancer 2006; 13: 1195-1202. doi: 10.1677/erc. 1.01220

[21] Hoegerle S, Nitzsche E, Altehoefer C et al. Pheochromocytomas: Detection with 18F DOPA whole-body PET-initial results. Radiology 2002; 222: 507-512. doi: 10.1148/radiol.2222010622 
[22] Edström Elder E, Hjelm Skog AL, Höög A et al. The management of benign and malignant pheochromocytoma and abdominal paraganglioma. Eur J Surg Oncol 2003; 29: 278-283. doi: 10.1053/ ejso.2002.1413

[23] Brunt LM, Bennett HF, Teefey SA et al. Laparoscopic ultrasound imaging of adrenal tumors during laparoscopic adrenalectomy. Am J Surg 1999; 178: 490-494. doi: 10.1016/S0002-9610(99)00220-2

[24] Schwerk WB, Gorg C, Gorg K et al. Adrenal pheochromocytomas: A broad spectrum of sonographic presentation. J Ultrasound Med 1994; 13: 517-521. doi: 10.7863/jum.1994.13.7.517

[25] Collienne M. Endosonographische Charakteristika und longitudinale Verlaufskontrolle hormonellinaktiver Nebennierenläsionen und des subklinischen Cushing-Syndroms [Dissertation]. Marburg: University Marburg; 2015
[26] Ilias I, Pacak K. Current Approaches and Recommended Algorithm for the Diagnostic Localization of Pheochromocytoma. J Clin Endocrinol Metab 2004; 89: 479-491. doi: 10.1210/jc.2003-031091

[27] Rockall AG, Reznek RH. Imaging of neuroendocrine tumours (CT/MR/ US). Best Pract Res Clin Endocrinol Metab 2007; 21: 43-68. doi: 10.1016/j.beem.2007.01.003

[28] Kurisaki-Arakawa A, Saito T, Takahashi M et al. A case of (123)I-MIBG scintigram-negative functioning pheochromocytoma: immunohistochemical and molecular analysis with review of literature. Int J Clin Exp Pathol 2014; 15: 4438-4447

[29] Blake MA, Cronin CG, Boland GW. Adrenal imaging. Am J Roentgenol 2010; 194: 1450-1460. doi: 10.2214/AJR.10.4547

[30] Dietrich CF. Endosonographie. Stuttgart: Georg Thieme Verlag; 2008. doi: 10.1055/b-002-39797 